\title{
Telemonitoring of home exercise cycle training in patients with COPD
}

\author{
This article was published in the following Dove Press journal: \\ International Journal of COPD \\ II November 2016 \\ Number of times this article has been viewed
}

\author{
Karl-Josef Franke ${ }^{1,2}$ \\ Ulrike Domanski' \\ Maik Schroeder' \\ Volker Jansen ${ }^{3}$ \\ Frank Artmann ${ }^{4}$ \\ Uwe Weber ${ }^{5}$ \\ Rainer Ettler ${ }^{6}$ \\ Georg Nilius ${ }^{1,2}$ \\ 'Department of Pneumology and \\ Critical Care Medicine, Helios Klinik \\ Ambrock, Hagen, ${ }^{2}$ Witten/Herdecke \\ University, Witten, ${ }^{3}$ Lung Practice \\ Jansen, Menden, ${ }^{4}$ Aeroprax \\ Wuppertal, Wuppertal, ${ }^{5}$ Lung \\ Practice Witten, Witten, 'ung \\ Practice Ettler, Hagen, Germany
}

\begin{abstract}
Background: Regular physical activity is associated with reduced mortality in patients with chronic obstructive pulmonary disease (COPD). Interventions to reduce time spent in sedentary behavior could improve outcomes. The primary purpose was to investigate the impact of telemonitoring with supportive phone calls on daily exercise times with newly established home exercise bicycle training. The secondary aim was to examine the potential improvement in health-related quality of life and physical activity compared to baseline.

Methods: This prospective crossover-randomized study was performed over 6 month in stable COPD patients. The intervention phase (domiciliary training with supporting telephone calls) and the control phase (training without phone calls) were randomly assigned to the first or the last 3 months. In the intervention phase, patients were called once a week if they did not achieve a real-time monitored daily cycle time of 20 minutes. Secondary aims were evaluated at baseline and after 3 and 6 months. Health-related quality of life was measured by the COPD Assessment Test (CAT), physical activity by the Godin Leisure Time Exercise Questionnaire (GLTEQ).

Results: Of the 53 included patients, 44 patients completed the study (forced expiratory volume in 1 second $47.5 \% \pm 15.8 \%$ predicted). In the intervention phase, daily exercise time was significantly higher compared to the control phase (24.2 \pm 9.4 versus $19.6 \pm 10.3$ minutes). Compared to baseline (17.6 \pm 6.1 ), the CAT-score improved in the intervention phase to $15.3 \pm 7.6$ and in the control phase to $15.7 \pm 7.3$ units. The GLTEQ-score increased from 12.2 \pm 12.1 points to $36.3 \pm 16.3$ and $33.7 \pm 17.3$.
\end{abstract}

Conclusion: Telemonitoring is a simple method to enhance home exercise training and physical activity, improving health-related quality of life.

Keywords: telehealthcare, physical activity, COPD assessment test, telephone support

\section{Introduction}

Chronic obstructive pulmonary disease (COPD) is an important disease worldwide, with increasing rates of morbidity and mortality; it is estimated that COPD will become the fourth-most common cause of death by $2020 .{ }^{1}$ Compared to healthy peers, patients with COPD show significantly lower levels of physical activity. Moreover, the deterioration already occurs early in the course of the disease. ${ }^{2-9}$

Donaire-Gonzalez et al found, that only one-quarter of 177 patients with a mean forced expiratory volume in 1 second $\left(\mathrm{FEV}_{1}\right)$ of $52 \%$ predicted was physically active for at least 30 consecutive minutes on at least 5 days. ${ }^{10}$ Low physical activity levels in COPD patients are on the other side associated with a significantly increased risk of hospital admissions, which can relevantly be diminished by regular physical activity like cycling or walking for only $2 \mathrm{~h}$ per week. ${ }^{11-15}$ Low physical activity levels of patients with COPD are also correlated with an increased risk of dying. ${ }^{13,15,16}$ Compared to established predictors of survival in COPD like the BODE (body mass index, airway obstruction,
Correspondence: Karl-Josef Franke Department of Pneumology and Critical Care Medicine, HELIOS Klinik Ambrock, Ambrocker Weg 60, 5809I Hagen, Germany

Tel +49 233। 9742002

Fax +49 233I 9742009

Email karl-josef.franke@helios-kliniken.de
International Journal of COPD 2016: | | 282I-2829

(c) (1) (8) ( 2016 Franke et al. This work is published and licensed by Dove Medical Press Limited. The full terms of this license are avalable at https://www.dovepress.com/terms.php cc) hereby accept the Terms. Non-commercial uses of the work are permitted without any further permission from Dove Medical Press Limited, provided the work is properly atributed. For permision for commercial use of this work, please see paragraphs 4.2 and 5 of our Terms (htpps://www.dovepress. com/terms.php). 
dyspnea, exercise capacity) index and the ADO (age, dyspnea, airway obstruction) index, physical activity is the strongest predictor of all-cause mortality. ${ }^{16}$ Again, cycling or walking for at least $2 \mathrm{~h}$ per week versus less than $2 \mathrm{~h}$ per week means a $30 \%$ reduced respiratory-related mortality, indicating a better prognosis for patients who remain physically active. ${ }^{13}$

The association between being less physically active and expecting poor clinical outcomes, including beneficial effects of treatment, underpins the importance to enhance the level of physical activity in COPD patients in daily life. Pulmonary rehabilitation increases exercise capacity in patients with COPD, but the vast majority of studies demonstrates a lack of improvement regarding the effect on physical activity. ${ }^{17-22}$ Yet, exercise training - not necessarily as part of pulmonary rehabilitation - may increase physical activity. ${ }^{23}$

Therefore, establishing home exercise training could be considered a simple method to implement regular physical activity in patients with COPD. But because of a lack of adherence, motivational strategies are needed to initiate and maintain behavioral changes and to enhance physical activity. ${ }^{24,25}$ Supporting phone calls, every other day for example, increased regular physical activity in patients with stable severe COPD at least for a short time. ${ }^{26}$

Telehealthcare is a novel option to promote physical activity in patients with COPD. Patients report their physical activity via internet and/or phone and receive feedback and goal-settings as well as motivation and support concerning self-care. ${ }^{27,28}$

In the present study, telehealthcare was used more simply without requesting patients to report: training times of home exercise cycle training were recorded and immediately transferred to the server of the clinic in real time. The primary aim was to compare daily exercise times in patients with stable COPD, either with or without supporting phone calls. Patients were called during the intervention phase, when a determined daily exercise time was not achieved. Secondary aim was to explore the impact of such training on healthrelated quality of life (HRQOL) and regular physical activity compared to baseline.

\section{Methods}

This prospective crossover-randomized study was approved by the ethics committee of the Witten/Herdecke University under number 43/2010 and was registered at ClinicalTrials. gov, identifier NCT 01987544. Participants gave their written informed consent.

\section{Patients}

COPD patients with Global Initiative for Chronic Obstructive Lung Disease (GOLD) grade 2-4 airflow limitation (moderate to very severe $)^{29}$ were eligible in a stable phase of their disease. After inclusion, patients were classified as belonging to GOLD Group A, B, C, or D of the combined COPD assessment. ${ }^{30}$ Exclusion criteria were a malignant or a symptomatic cardiac disease.

\section{Study design}

COPD patients were informed about the clinical study when coming to a routine checkup visit at practices of a network of participating pulmonologists. Prior to inclusion, the home exercise cycle training was explained and recommended to eligible patients. The consenting patients were randomized to the study using a previously created randomization list, and the baseline assessments were forwarded to the coordinating clinic. The descriptive data included lung function and 6-minute walking distance. ${ }^{31-33}$ Dyspnea severity at baseline was measured by the modified Medical Research Council (mMRC) dyspnea scale. ${ }^{34}$ Patients received a bicycle ergometer with a personal introduction at home. The workload of the cycle training was adjusted to meet patients' capability to endure for at least 30 minutes, yet patients were free to re-adjust their workload at home. The resistance level was not monitored throughout the study.

\section{Intervention and outcome measures}

The ergometer training was monitored during the following 6 months after inclusion, while motivational phone calls were randomly assigned to the first or the second 3 month period (intervention period versus control period) (Figure 1). All patients were instructed to adhere to a daily training target of 30 minutes. Training times were evaluated at the end of each week. In the intervention period, patients were called by telephone when they did not achieve an average weekly training time of at least 20 minutes per day. No phone calls took place during the 3 months control period.

The primary outcome measure was the mean daily exercise time in the intervention period compared to the control period.

To evaluate secondary aims, measurements of all patients took place at baseline, and 3 and 6 months after baseline (Figure 1).

1. HRQL was measured by the COPD Assessment Test (CAT). The test-retest responsivity of the CAT for COPD patients after rehabilitative interventions is comparable to that of other quality of life questionnaires. ${ }^{35}$ The CAT's minimal clinically important difference (MCID) probably amounts to at least two units. ${ }^{36,37}$

2. The leisure time physical activity was recorded using the Godin Leisure Time Exercise Questionnaire (GLTEQ). 


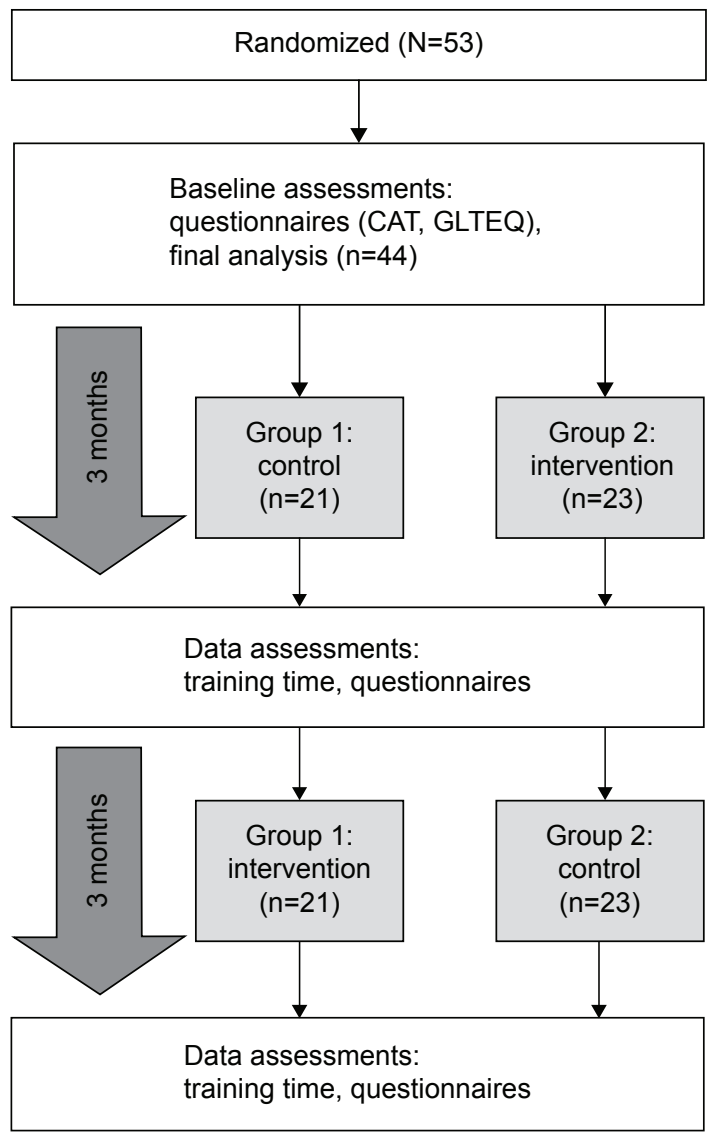

Figure I Study flow chart.

Abbreviations: CAT, COPD Assessment Test; GLTEQ, Godin Leisure Time Exercise Questionnaire.

The questionnaire records frequency and intensity of leisure time physical exercise of more than 15 minutes during the last 7 days. To characterize the amount of physical activity the Godin Total Leisure Activity (TLA) score is calculated. ${ }^{38}$

\section{Telephone calls}

The phone calls were semi-structured. All patients were asked to assess their physical condition and to compare it to the week before, to assess their motivation to proceed with the training, and they were questioned regarding problems with the training and for an estimation of their daily exercise time. The phone call allowed to ask for the cause of a diminished training time and to encourage patients to increase their training. The duration of the phone calls was limited to a maximum of 5 minutes per call.

\section{Telemonitoring}

To automatically capture and transfer the training data, the bicycle ergometers were equipped with a data transmission system (Global System for Mobile Communication (GSM) module TC-65 with an integrated micro-Controller (Siemens,
Munich, Germany)). A magnetic switch recorded pedal movements with a latency of 15 seconds to log the beginning of the training. 15 seconds after having finished the training, the acquired time was sent anonymously to the server of the hospital. Pilot studies proofed this system to allow an effective and economic transfer of training times. ${ }^{39,40}$

\section{Statistics}

Daily training time was real-time monitored for every patient. The primary outcome - mean daily training time - was calculated for both phases (intervention and control) after the completion of the study.

An increase in training time of 5 minutes at a prescribed time of 30 minutes was regarded relevant. A standard deviation of 10 minutes was assumed with regard to a pretrial investigation. ${ }^{39}$ With a statistical probability of alpha $=0.05$ for type 1 error and beta $=0.1$ for the type 2 error an estimated sample size of at least 42 patients had to be considered. Because of an expected number of $5 \%-10 \%$ discontinuing the study, ${ }^{41}$ a total number of 50 study participants was planned.

The following hypotheses (H0, H1) were set to compare the main study objective (training time):

H0: The mean training time per day in the control group equals the mean training time in the intervention group. H1: The mean training time per day in the intervention group is higher. H0 is rejected at $\rho>0.05$. The applied statistical method is the Student's $t$-test.

Secondary outcomes: evaluated scores of both questionnaires (CAT, GLTEQ) after 3 (juncture of cross-over) and after 6 months were calculated after the completion of the study for both phases (intervention and control) and compared to baseline scores. Furthermore, scores of both groups together (Figure 1) after 3 and 6 months compared to baseline.

Collected data were evaluated for means and standard deviations. For not continuous variables, medians and interquartile ranges were reckoned.

\section{Results}

A total of 53 patients were included (Figure 1). 2 patients had to be excluded after randomization, but before starting training (1 newly diagnosed critical aortic aneurysm; 1 because of failed telemonitoring technique because of lacking network in rural environment). 3 further patients had to be excluded for medical reasons during the study period (1 newly diagnosed lung cancer; one newly diagnosed spinal cyst, and one newly diagnosed groin abscess, both with severe pain). 1 of these patients stopped exercise after having completed the intervention phase, and 2 after having 
completed control phases. 4 patients withdrew their consent during the course of the study, reasons were discomfort with the saddle resulting in pain (2), and because the daily exercise program was thought to be too time consuming (2).

The data of 44 patients ( $63.3 \pm 7.8$ years, 23 female) who finished the study were analyzed (Figure 1). With regard to the combined COPD assessment, 3 patients belonged to GOLD Group A, 14 to Group B, 2 had to be assigned to C, and 25 patients - suffering most from their disease - to GOLD Group D. Further patient characteristics are described in Table 1.

\section{Primary objective}

Daily training time during the intervention phase with telephone support was significantly superior to daily training time during the control phase without telephone motivation

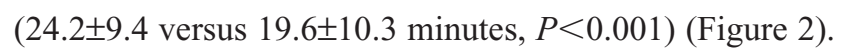
An average of $2.9 \pm 2.9$ motivational phone calls per patient were necessary during the intervention phase because patients did not meet the determined minimum daily exercise time. When the intervention period was randomized to the first 3 months, the training time in this period was higher compared to daily training times in the intervention phase when randomized to the last 3 months $(26.7 \pm 8.4$ versus 21.5 \pm 9.9 minutes, $P=0.066$ ), (Figure 3).

For the 25 patients belonging to Group D in accordance with the GOLD criteria of the combined COPD assessment,

Table I Patients' characteristics

\begin{tabular}{lll}
\hline Characteristics & Mean & SD \\
\hline Age $($ years $)$ & 63.3 & 7.8 \\
Height $(\mathrm{cm})$ & 168.8 & 7.9 \\
Weight $(\mathrm{kg})$ & 69.3 & 16.9 \\
BMI & 24.3 & 5.2 \\
6 MWD (m) & 384.3 & 102.6 \\
FEV $(\%$ predicted) & 47.5 & 15.8 \\
RV $(\%$ predicted) & 203.6 & 80.0 \\
CAT score & 17.6 & 6.1 \\
TLA score & 12.2 & 12.1 \\
& Median & IQR \\
BODE score & 3 & 3 \\
mMRC dyspnea score & 2 & 1 \\
& $\mathbf{N}$ & \\
COPD GOLD 4 & 6 & \\
COPD GOLD 3 & 20 & \\
COPD GOLD 2 & 18 & \\
Female & 24 &
\end{tabular}

Abbreviations: BMI, body mass index; 6 MWD, 6-minute walking distance; mMRC, modified Medical Research Council; $\mathrm{FEV}_{1}$, forced expiratory volume in I second; RV, residual volume; BODE, body mass index, airway obstruction, dyspnea, exercise capacity; CAT, COPD Assessment Test; TLA, Godin Total Leisure Activity; $\mathrm{N}$, number of patients; SD, standard deviation; IQR, interquartile range; COPD, chronic obstructive pulmonary disease.

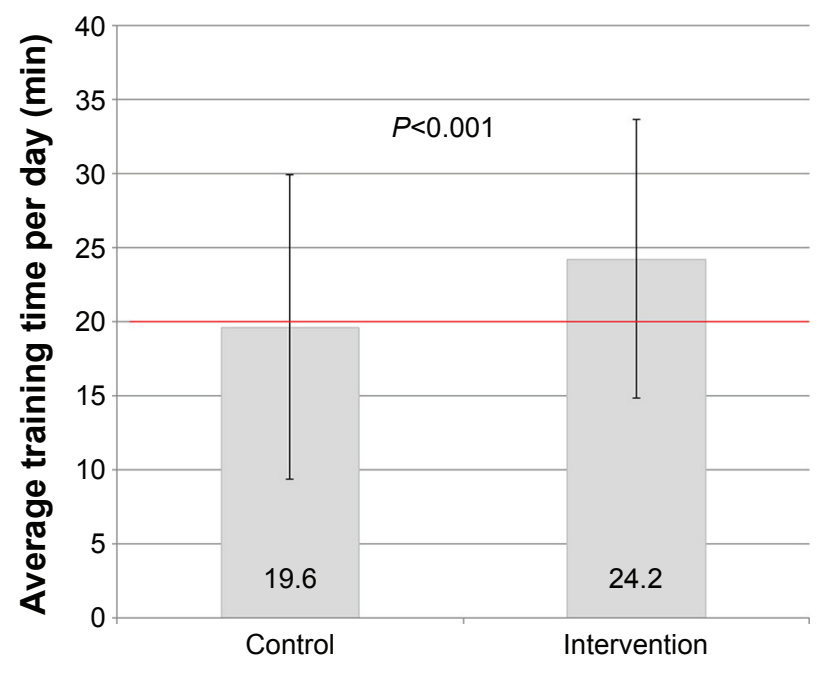

Figure 2 Primary objective: daily training times compared between intervention and control period, $\mathrm{n}=44$.

the difference in daily training time amounted to $23.1 \pm 9.1$ (intervention phase) versus $18.1 \pm 11.2$ minutes (control phase).

During the intervention phase, patients stayed below a daily exercise time of 20 minutes on only $23.1 \pm 18.8$ days, which is in accordance with $31.0 \% \pm 25.2 \%$ of a total of $76.9 \pm 11.7$ training days. During the control phase a training time of less than 20 minutes was recorded on $30.0 \pm 24.3$ days - equivalent to $39.7 \% \pm 3.8 \%$ of a total of $78.2 \pm 9.3$ training days.

\section{Secondary objectives}

1. The CAT score, compared to baseline, improved in the intervention as well as in the control phase amounting to around 2 units. The mean baseline CAT score of all patients came to $17.6 \pm 6.1$ and improved after the intervention phase to $15.3 \pm 7.6(P=0.006)$ and after the control phase to $15.7 \pm 7.3$ units $(P=0.023)$. Thus, the intervention period and the control period did not differ significantly referring to the CAT score $(P=0.71)$, (Figure 3$)$.

Independent of the randomized study periods, the CAT score improved in the whole group to $15.4 \pm 8.0$

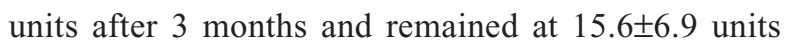
after 6 months. In patients belonging to GOLD Group D $(n=25)$ the CAT score declined from baseline 18.9 \pm 5.2 to $16.0 \pm 7.5$ units after the intervention and to $16.2 \pm 7.2$ units after the control phase.

2. At baseline, the TLA score of the GLTEQ was at $12.2 \pm 12.1$ points. The score increased significantly in both randomized study phases, after intervention to $36.3 \pm 16.3$ and after the control phase to $33.7 \pm 17.3$ points $(P<0.001$ each). The difference between intervention phase and 


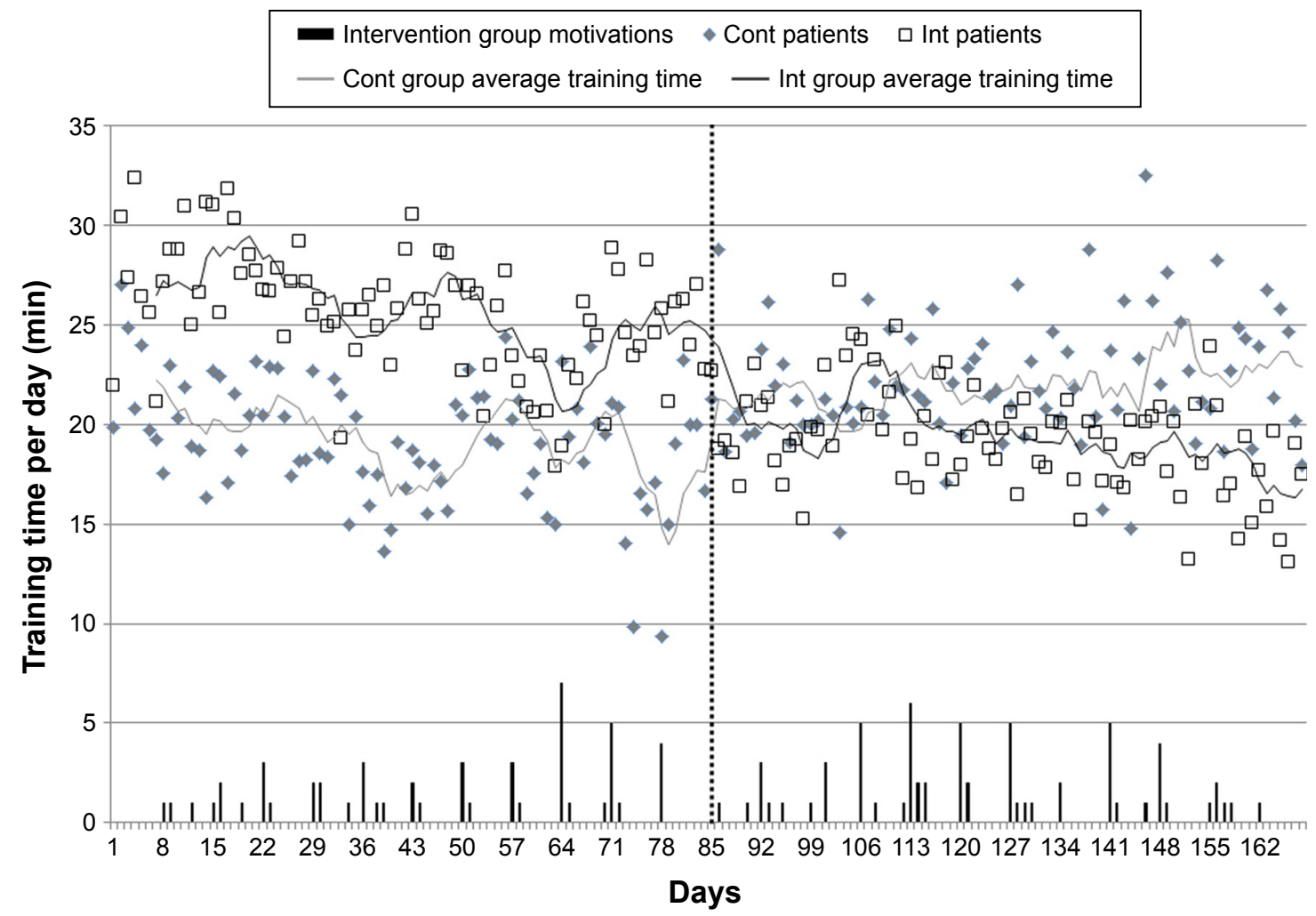

Figure 3 Daily training times in the chronological course of the crossover study.

Notes: Cont: patients randomized to control phase first; Int: patients randomized to intervention phase first.

control phase was not significant (36.3 \pm 16.3 versus $33.7 \pm 17.3, P=0.24$ ), (Figure 4). Independent of the randomized study periods, the TLA score improved in the whole group after 3 months to $36.1 \pm 15.1$ and after 6 months to $33.9 \pm 18.4$ points.

GOLD Group D patients $(\mathrm{n}=25)$ improved in the GLTEQ score from baseline, $10.3 \pm 8.5$ to $38.6 \pm 15.9$ points after intervention and to $37.5 \pm 16.6$ points after the control phase.

\section{Discussion}

The presented study was set up to investigate the effects of simple, domiciliary bicycle ergometer training with telemetric monitoring in moderate to very severe COPD patients. Regular

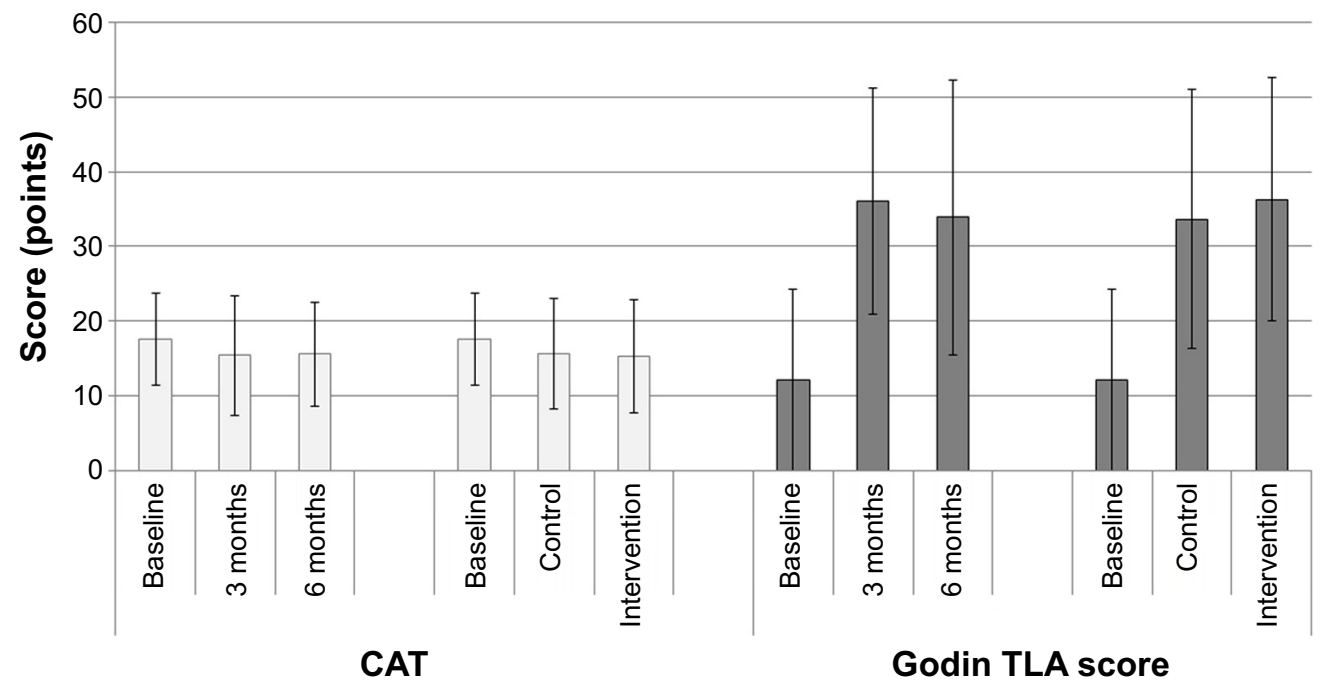

Figure 4 Secondary objectives: CAT (COPD Assessment Test) score and Godin TLA (Total Leisure Activity) score after 3 and after 6 months, and after intervention and control period compared to baseline, $\mathrm{n}=44$. 
physical activity - described by the transmitted training times and the GLTEQ score - was significantly enhanced by such monitored training over a 6 month period. And as a consequence of the training, there was a clinically meaningful improvement in HRQOL. A telephone intervention, only required when the patient undercuts a predefined training duration, may in addition increase daily training times.

\section{Telephone motivation as required enhances physical activity}

Our telephone encouragement successfully increased the daily exercise cycle time at home (Figure 2). Motivational interviewing techniques are helpful to bring about behavioral changes in COPD patients. ${ }^{41}$ Hereby, telephone counseling of outpatient COPD patients is not a new method to improve their adherence to therapy. Ries et al surveyed the efficacy of a telephone-based maintenance program after pulmonary rehabilitation with weekly phone calls over 12 months in a comparable group of patients with moderate to severe COPD. ${ }^{42}$ The experimental group maintained exercise tolerance better than the control group, yet the trial lacked a measurement of physical activity. A conclusion concerning physical activity is limited by the fact that an improvement of exercise capacity is not closely associated with an increase of self-determined leisure time physical activity. ${ }^{24}$

As mentioned above, daily physical activity measured by electronic actigraph counts in patients with severe to very severe COPD in a stable stage of their disease was significantly raised due to regular telephone calls on every second day. ${ }^{26}$ Patients in this study differed from our patient group in terms of disease severity $(32.3 \% \pm 9.4 \%$ versus $47.5 \% \pm 15.8 \%$ of the predicted value for $\mathrm{FEV}_{1}$ ), and the period of the investigation comprised only 2 weeks. Yet, the given target of regular in-home exercise to increase daily physical activity and the simple telephone support without a complex intervention program were comparable to our data.

Other studies, that found an improvement in physical activity compared to control groups without prior rehabilitation, applied a complex program with self-monitoring and education to enhance self-management and self-efficacy to the intervention arms. ${ }^{27,28}$ Nguyen et al also included a reinforcement by regular phone calls of 5-10 minutes once and two times per week, respectively. ${ }^{27}$ Patients with stable moderate to severe COPD in this study were assigned to 2 different intervention groups, and both showed a significant improvement in weekly training times of home endurance exercise training in terms of walking, cycling, or swimming, compared to a control group after 12 months (221 and
208 versus 115 minutes). This would equate to a maximum daily training time of 31.5 minutes, albeit following a complex intervention process and with unsupervised independent exercise training.

\section{Telehealthcare as real-time telemonitoring}

Contrary to most published studies, our presented research aimed at increasing regular physical activity by implementing simple home exercise training with reinforcement through telemetric surveillance. Up to date, conventional methods as well as telehealthcare techniques via internet or mobile phone are based upon data from self-monitoring and consecutive patient reports to support exercise training of patients with COPD. ${ }^{43}$ In the presented study, we used telehealthcare techniques as real-time telemonitoring, with a remote transmission of exercise times with a latency of only 15 seconds after registration. The training data were monitored regarding a potential telephone intervention. That facilitated the intervention program, because motivational phone calls took place only when required. Less than three telephone calls per patient were accomplished on average during the 3 month intervention phase - thus only one call per patient per month. Therefore, the presented method seems to be easy to implement in everyday life. Educated staff of general practitioners or pulmonologists could be entrusted with the task to survey the training.

\section{Improvement of physical activity levels and quality of life by means of monitored training}

The low baseline TLA score of the GLTEQ (12.2 \pm 12.1 points, Table 1 and Figure 4) - representing the last week before patients started their home exercise cycle training - aligns with the level of regular physical activity that is known to be already considerably reduced in COPD patients with just moderate airflow limitation. Less than half of patients are moderately physically active for at least 30 minutes per day, also if the duration of activity is divided into several shorter bouts per day. ${ }^{10,44,45}$

The TLA score increased in both of our study arms, up to $36.3 \pm 16.3$ (intervention) and $33.7 \pm 17.3$ (control) points, respectively. That increase reflects the newly - in the context of the study - started home exercise cycle training. The physical activity level of our patients was thus improved by a simple method. On the one hand, an exercise device was made available. On the other hand, the real-time telemonitoring surveillance was already perceived as 
supportive, resulting in a significantly higher TLA score in relation to baseline, also in the control arm without any counseling by telephone.

The CAT score reduction of more than 2 units versus baseline in the intervention and control arm indicates an improvement in HRQL, which is induced by the enhancement of regular physical activity. Two other studies that investigated an exercise intervention also found a moderate improvement in HRQL. ${ }^{27,28}$ Moy et al used an Internetmediated, pedometer-based exercise intervention. In fact, the St George's Respiratory Questionnaire total score did not improve significantly after 4 months compared to control, yet a significantly larger proportion of patients in the intervention group showed at least a 4-unit improvement, which is considered the MCID. At the same time, patients in the intervention group also significantly increased their mean daily step counts. ${ }^{28}$ Yet, the association of physical activity and HRQL is still up for discussion. It also remains equally uncertain, whether a CAT score reduction of 2 units already reliably meets the MCID. ${ }^{36,37}$

Most affected patients in GOLD Group D of the combined COPD assessment achieved an improvement in quality of life of almost 3 units, and the increase in the TLA score also surpassed that of the total group, while exercise duration per day in Group D was only about 1 minute shorter. That implies that domiciliary training with telemonitoring might be useful therapy, particularly for severely afflicted patients.

\section{Strengths and limitations}

The study was accomplished in a very close approach to clinical practice. The major strength of this study is the implementation of an easy-to-handle procedure. Nearly all patients should be able to accomplish training at home with a simple exercise ergometer, which can be used regardless of weather conditions or details of their home environments. Referring to the GSM surveillance, there is no need for special education. Motivational phone calls are only occasionally performed and only a small amount of time is required.

Yet, the limitations of this study need attention as well. First, we chose a case-crossover design with the absence of a control group. The reason for that was to reduce the number of patients to be recruited. But, this resulted in potential bias: patients who started with the intervention achieved a higher daily training time in the intervention as well as in the control phase compared to the phases of patients who were first randomized to the control phase (Figure 3).

Furthermore, we did not record the number of eligible patients approached by the resident doctors to participate in the study. Therefore, this study is not applicable to determine the percentage of COPD patients to be motivated to enhance their daily physical activity by means of such an intervention program. But, the aim of the study was rather that of a pilot study to prove feasibility. Before a widespread implementation, more studies with a considerably larger number of patients and over longer periods of time are required.

\section{Conclusion}

Home exercise cycle training is able to improve regular physical activity and HRQOL in patients with COPD in a stable phase of their disease. Therefore, simple telemonitoring with supporting phone calls if required, seems efficient to trigger a necessary change in behavior, at least over a period of 6 months.

\section{Acknowledgment}

The study was financially supported by Vitaphone, Germany, concerning the purchase of the bicycle ergometers and the GSM modules. The company had no influence on the study itself, either on designing and accomplishing it, or on data analysis and interpretation.

\section{Disclosure}

Karl-Josef Franke, Ulrike Domanski, Maik Schroeder, Volker Jansen, Frank Artmann, Uwe Weber, Rainer Ettler and Georg Nilius declare that they have no financial involvement in the subject discussed in the submitted manuscript and that there are no conflicts of interest in this work.

\section{References}

1. Murray CJ, Lopez AD. Measuring the global burden of disease. N Engl J Med. 2013;369(5):448-457.

2. Pitta F, Troosters T, Spruit MA, Probst VS, Decramer M, Gosselink R. Characteristics of physical activities in daily life in chronic obstructive pulmonary disease. Am J Respir Crit Care Med. 2005;171(9): 972-977.

3. Troosters T, Sciurba F, Battaglia S, et al. Physical inactivity in patients with COPD, a controlled multi-center pilot-study. Respir Med. 2010; 104(7):1005-1011.

4. Watz H, Waschki B, Meyer T, Magnussen H. Physical activity in patients with COPD. Eur Respir J. 2009;33(2):262-272. Erratum in: Eur Respir J. 2010;36(2):462

5. Gouzi F, Préfaut C, Abdellaoui A, et al. Evidence of an early physical activity reduction in chronic obstructive pulmonary disease patients. Arch Phys Med Rehabil. 2011;92(10):1611-1617.e2.

6. Waschki B, Spruit MA, Watz H, et al. Physical activity monitoring in COPD: compliance and associations with clinical characteristics in a multicenter study. Respir Med. 2012;106(4):522-530.

7. Vorrink SN, Kort HS, Troosters T, Lammers JW. Level of daily physical activity in individuals with COPD compared with healthy controls. Respir Res. 2011;12:33. 
8. Shrikrishna D, Patel M, Tanner RJ, et al. Quadriceps wasting and physical inactivity in patients with COPD. Eur Respir J. 2012;40(5): $1115-1122$.

9. Van Remoortel H, Hornikx M, Demeyer H, et al. Daily physical activity in subjects with newly diagnosed COPD. Thorax. 2013;68(10): 962-963.

10. Donaire-Gonzalez D, Gimeno-Santos E, Balcells E, et al. Physical activity in COPD patients: patterns and bouts. Eur Respir J. 2013;42(4): 993-1002.

11. Pitta F, Troosters T, Probst VS, Spruit MA, Decramer M, Gosselink R. Physical activity and hospitalization for exacerbation of COPD. Chest. 2006;129(3):536-544.

12. Garcia-Aymerich J, Farrero E, Félez MA, Izquierdo J, Marrades RM, Antó JM; Estudi del Factors de Risc d'Agudització de la MPOC investigators. Risk factors of readmission to hospital for a COPD exacerbation: a prospective study. Thorax. 2003;58(2):100-105.

13. Garcia-Aymerich J, Lange P, Benet M, Schnohr P, Antó JM. Regular physical activity reduces hospital admission and mortality in chronic obstructive pulmonary disease: a population based cohort study. Thorax. 2006;61(9):772-778.

14. Benzo RP, Chang CC, Farrell MH, et al. Physical activity, health status and risk of hospitalization in patients with severe chronic obstructive pulmonary disease. Respiration. 2010;80(1):10-18.

15. Garcia-Rio F, Rojo B, Casitas R, et al. Prognostic value of the objective measurement of daily physical activity in patients with COPD. Chest. 2012;142(2):338-346.

16. Waschki B, Kirsten A, Holz O, et al. Physical activity is the strongest predictor of all-cause mortality in patients with COPD: a prospective cohort study. Chest. 2011;140(2):331-342.

17. Coronado M, Janssens JP, de Muralt B, Terrier P, Schutz Y, Fitting JW. Walking activity measured by accelerometry during respiratory rehabilitation. J Cardiopulm Rehabil. 2003;23(5):357-364.

18. Steele BG, Belza B, Cain KC, et al. A randomized clinical trial of an activity and exercise adherence intervention in chronic pulmonary disease. Arch Phys Med Rehabil. 2008;89(3):404-412.

19. Mador MJ, Patel AN, Nadler J. Effects of pulmonary rehabilitation on activity levels in patients with chronic obstructive pulmonary disease. J Cardiopulm Rehabil Prev. 2011;31(1):52-59.

20. Egan C, Deering BM, Blake C, et al. Short term and long term effects of pulmonary rehabilitation on physical activity in COPD. Respir Med. 2012;106(12):1671-1679.

21. Spruit MA, Singh SJ, Garvey C, et al. An official American Thoracic Society/European Respiratory Society statement: key concepts and advances in pulmonary rehabilitation. Am J Respir Crit Care Med. 2013; 188(8):e13-e64.

22. McCarthy B, Casey D, Devane D, Murphy K, Murphy E, Lacasse Y. Pulmonary rehabilitation for chronic obstructive pulmonary disease. Cochrane Database Syst Rev. 2015;2:CD003793.

23. Cindy Ng LW, Mackney J, Jenkins S, Hill K. Does exercise training change physical activity in people with COPD? A systematic review and meta-analysis. Chron Respir Dis. 2012;9(1):17-26.

24. Altenburg WA, ten Hacken NH, Bossenbroek L, Kerstjens HA, de Greef MH, Wempe JB. Short- and long-term effects of a physical activity counselling programme in COPD: a randomized controlled trial. Respir Med. 2015;109(1):112-121.

25. Walters JA, Cameron-Tucker H, Courtney-Pratt H, et al. Supporting health behaviour change in chronic obstructive pulmonary disease with telephone health-mentoring: insights from a qualitative study. $B M C$ Fam Pract. 2012;13:55.

26. Wewel AR, Gellermann I, Schwertfeger I, Morfeld M, Magnussen H, Jörres RA. Intervention by phone calls raises domiciliary activity and exercise capacity in patients with severe COPD. Respir Med. 2008; 102(1):20-26.
27. Nguyen HQ, Donesky D, Reinke LF, et al. Internet-based dyspnea selfmanagement support for patients with chronic obstructive pulmonary disease. J Pain Symptom Manage. 2013;46(1):43-55.

28. Moy ML, Collins RJ, Martinez CH, et al. An Internet-Mediated Pedometer-Based Program Improves Health-Related Quality-of-Life Domains and Daily Step Counts in COPD: A Randomized Controlled Trial. Chest. 2015;148(1):128-137.

29. Rabe KF, Hurd S, Anzueto A, et al. Global strategy for the diagnosis, management, and prevention of chronic obstructive pulmonary disease: GOLD executive summary. Am J Respir Crit Care Med. 2007;176(6): $532-555$.

30. Vestbo J, Hurd SS, Agustí AG, et al. Global strategy for the diagnosis, management, and prevention of chronic obstructive pulmonary disease: GOLD executive summary. Am J Respir Crit Care Med. 2013;187(4): 347-365.

31. Brooks D, Solway S, Gibbons WJ. ATS statement on six-minute walk test. Am J Respir Crit Care Med. 2003;167(9):1287.

32. Miller MR, Hankinson J, Brusasco V, et al. Standardisation of spirometry. Eur Respir J. 2005;26(2):319-338.

33. Wanger J, Clausen JL, Coates A, et al. Standardisation of the measurement of lung volumes. Eur Respir J. 2005;26(3):511-522.

34. Bestall JC, Paul EA, Garrod R, Garnham R, Jones PW, Wedzicha JA. Usefulness of the Medical Research Council (MRC) dyspnoea scale as a measure of disability in patients with chronic obstructive pulmonary disease. Thorax. 1999;54(7):581-586.

35. Gupta N, Pinto LM, Morogan A, Bourbeau J. The COPD assessment test: a systematic review. Eur Respir J. 2014;44(4):873-884.

36. Tsiligianni IG, van der Molen T, Moraitaki D, et al. Assessing health status in COPD. A head-to-head comparison between the COPD assessment test (CAT) and the clinical COPD questionnaire (CCQ). BMC Pulm Med. 2012;12:20.

37. Kon SS, Canavan JL, Jones SE, et al. Minimum clinically important difference for the COPD Assessment Test: a prospective analysis. Lancet Respir Med. 2014;2(3):195-203.

38. Godin G, Shephard RJ. A simple method to assess exercise behavior in the community. Can J Appl Sport Sci. 1985;10(3):141-146.

39. Rühle KH, Bloch M, Franke KJ, Nilius G. Telemonitoring von Armergometer-Training bei COPD-Patienten. Eine Pilotstudie [Telemonitoring of arm ergometric training in COPD patients. A pilot study]. Pneumologie. 2009;63(6):314-318. German.

40. Rühle KH, Franke KJ, Domanski U, Schröder M, Nilius G. Telemonitoring von Fahrrad-Heimtraining bei Patienten mit obstruktiver Schlafapnoe [Telemonitoring of bike exercise training in patients with obstructive sleep apnoea]. Pneumologie. 2013;67(6):321-326. German.

41. Greaves CJ, Sheppard KE, Abraham C, et al. Systematic review of reviews of intervention components associated with increased effectiveness in dietary and physical activity interventions. BMC Public Health. 2011;11:119.

42. Ries AL, Kaplan RM, Myers R, Prewitt LM. Maintenance after pulmonary rehabilitation in chronic lung disease: a randomized trial. Am J Respir Crit Care Med. 2003;167(6):880-888.

43. Lundell S, Holmner Å, Rehn B, Nyberg A, Wadell K. Telehealthcare in COPD: a systematic review and meta-analysis on physical outcomes and dyspnea. Respir Med. 2015;109(1):11-26.

44. Vitorasso R, Camillo CA, Cavalheri V, et al. Is walking in daily life a moderate intensity activity in patients with chronic obstructive pulmonary disease? Eur J Phys Rehabil Med. 2012;48(4):587-592.

45. van Remoortel H, Camillo CA, Langer D, et al. Moderate intense physical activity depends on selected Metabolic Equivalent of Task (MET) cut-off and type of data analysis. PLoS One. 2013;8(12):e84365. 
International Journal of COPD

\section{Publish your work in this journal}

The International Journal of COPD is an international, peer-reviewed journal of therapeutics and pharmacology focusing on concise rapid reporting of clinical studies and reviews in COPD. Special focus is given to the pathophysiological processes underlying the disease, intervention programs, patient focused education, and self management protocols.

This journal is indexed on PubMed Central, MedLine and CAS. The manuscript management system is completely online and includes a very quick and fair peer-review system, which is all easy to use. Visit http://www.dovepress.com/testimonials.php to read real quotes from published authors 